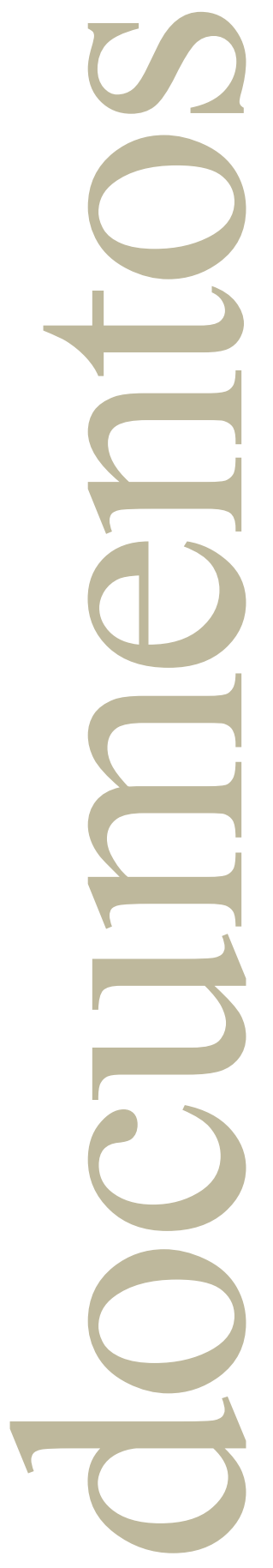

\title{
Universidad, patria sometida
}

Exhibimos, como material de nuestro archivo, una pieza clave para entender una crisis en Venezuela que viene creciendo desde hace varias décadas. La oportunidad celebratoria que aprovecha el rector Jesús M. Bianco para hablarle de frente a la Cámara de Diputados que aprobaba al vapor una reforma muy cuestionada en la opinión pública, culmen de un contexto de mucha represión y tensiones entre el Estado y la Central, es recordada como una ocasión fundamental en la historia de la universidad en Venezuela durante aquella primera presidencia de Rafael Caldera, esperanza vana, pues un partido de oposición se erguía en el gobierno por aparentes vías pacíficas.

El documento, vehemente, habla por sí mismo, es también un enérgico llamado a la cohesión razonada frente a la crisis que el gobierno había impuesto en esos días en las autonomías universitarias, a la postre estudiada a la altura del Cordobazo, y leído a la distancia y en el contexto actual, se puede entender como premonitorio, como una pieza que funciona para entender el espíritu de los tiempos actuales en aquel país.

Desconocemos el número de ejemplares del discurso que tiró la Imprenta Universitaria de Caracas, sin embargo creemos que pudieron ser cientos de miles, pues se trataba de un movimiento que unió igual a estudiantes, profesores y obreros. 


\section{UNIVERSIDAD}

avasallada,

PATRIA

más sojuzgada Discurso pronunciado por el Rector de
la Universidad Central de Venezuela, la Universidad Central de Venezuela,

$7070 \begin{aligned} & \text { en el acto solemne de graduación de } \\ & 232 \text { nuevos profesionales, en el Aula } \\ & \text { Magna, el jueves } 3 \text { de septiembre, } 24\end{aligned}$ Magna, el jueves 3 de septiembre, 24
horas después que la Cámara de Dipuboras después que la Cámara de Dipu-
tados sancionara la Reforma a la Ley de Universidades.

\section{UNIVERSIDA D \\ CENTR A L \\ DE VENEZUELA \\ la universidad de caracas \\ R E C T O R A D O}

UNIVERSIDAD CENTRAL. DE VENEZUELA

Dt. Jesús M. Bianco

Rectos

Dr. José Lucio Gonzilez Rivero

Vicerector

De. Victor Gonzílez Mendozz
Estos actos de graduación que tradicionalmente son ocasiones de regocijo y alegria, estin boy signados por la grave preocuración que embarga a todos los sectotes universitarios ante la importante disyuntiva de su propio destipo. Los interees subaltemos, de exclusiva utilidad para los sectores politicos que los inspiran, han colocado al Alma Máter, mediante una reforma legislativa apresurada, inconsulta, interesada $y$ secta ria, al borde de un abismo. Situación que tiene una projección aún mís trascendente, conso es la de atentar contra la juventud venezolana, contra su futuro y su misión genuina en la lucha por un destino superior para la patria. El cercenamiento del túgimen autonómico - realizado con inaudita soberbia, des. conociendo argumentos $y$ turones formulados piblicamente por los mís calificados sectores del pensumiento universitario na.

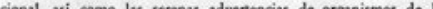
de organismos de il cultura y la ciencia sention expresión multitudimaria del pueblo venezolano- significa tambien el segat

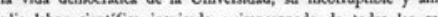
plia labor científica inspirada e impregnada de todas las corrientes del pensamiento universal; determina el cese de la 
función, celosamente mantenida; de salvaguardia de los mejores ideales de redención social; decreta la cessción de su crguida y clara labor de creación de conciencia nacional pura, no media. tizada, solo inspirada por el borixonte de la Venczuela presente y futura en cultivo de la herencia que nos legaron los liber. tadores.

\section{Una campaña de colonización}

Siento hoy el deber de llamar la atención de la ciudadania venezolana que permanece leal a los intereses supremos de nuestra patria sobre el origen, el sentido y los objetivos de campaña de colonización de que son objeto nuestras univer. sidades autónomas, nucstro sistema nacional de educación la sociedad venezolana misma

En cuanto al sentido de esa campaña de colonización, basta apuntar la movilización publicitaria de descrédito de Universidad que desde hace varios años utiliza todos los me dios de comunicación de masas para distorsionar la opinión pública.

Es de preguntar: ¿quiénes pagan esa campaña millonaris: ¿Serin acaso venezolanos los que la costean? ¿O setán las empresas extranjeras quienes están detrís de ella?

Después de apoderarse de todas las fuentes de riquezs de nuestro pais a través de concesiones y contratos de servicio

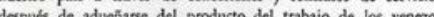
lanos meliante una industrialiandion por trob des corporaciones internacionales, estos seivores consideran in- dispensable dominar la única institución nacional que sigue siendo enteramente libre en nuestro pais, aquella en la que nuestra conciencia nacional puede expresarse lúcidamente y en la que se emprende la búsgueda de los caminos del desarrollo pleno y autónomo de nuestra patria: la universidad popular $y$ democritica.

\section{"Hay que podarlos"}

Estos objetivos fueton definidos por los estrategas de ti neocolonización de Venezvela como un tequisito indispensable

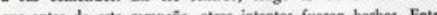
que antes de esta campana, orros intentos fueron hechos. Entre

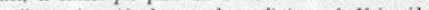
arrollo en el sentido de pretender mediatizat a la Universidas Central con préstamos de favot, del oeden de 30 millones de dólares. Un préstamo igual acaba de ser rechazado en docu. mento público pot la Universidad del Uruguay. En ese caso fue ofrecido por la orA a las naciones latinoamericanas regidas por las grandes corporaciones a trav's del manejo de gobiernos dóciles $y$ obsenuentes.

L clasificación del cercenamiento de la autonomia universitaria como objetivo itreductible de la estrategin de dominación foránea de nuestra Universidad, ya no puede set puesta en duda. Hace poces dias hicimos públicas por la prensa de la capital las declaracionos de empresarios norteamericanos to

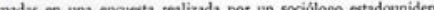
$x$, el doctor Frank Bonilla, y publicada en su estudio Las Elites
Invisibles. (Cendors, 1969). Uno de esos empresarios decia al sociólogo:

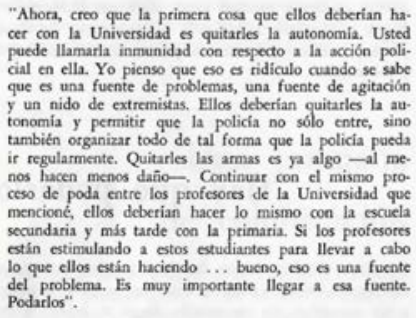

Es imposible ser mis clano: "hay que podarlos". Primero a la Universidad. Después a la escuela secundaria. Luego a la primaria. ¿Dónde quedarí nuestra libertad de formar nuestra propia juventud? Cómo cumpliremos nuestro deber de infunpropia juventud? ¿Como cumpliremos nuestro deber de infundir una ideologia nacional auténtica a las nuevas generaciones?
Lo más grave, sin embargo, es que se trata de un primer paso hacia la neocolonización que yz esth en curso y que tiene como objetivo último implantat un orden institucional en el que no haya condiciones para lachar contra la subyugación de nuestro pueblo. Luego de silenciar a la juventud universitaria come portavoz de la conciencia mis lócida de la nación, otros paseos seguirain hasta la medida final, que será la liquidación fisica

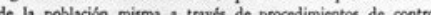

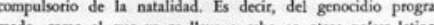
mado, como el que ya se lleva a cabo en otros paises latino-
L población aumente, ocupe todo el territorio nacional, se rejuvenezca continuamente y reclame su derecho a la vida, a i justicia, a la libertad y al comando autónomo del destino nacional.

A todos los niveles: un plan de dominación imperial

El pucblo venezolano precisa tomar conciencia de que lo que se esconde detris de esta campaña de colonización cultura en todos los niveles es un plan estratégico de dominación imperial. Ese es su objetivo. Ya no se satisfacen con explotar cl petroleo que cnriquece fabulosumente a las corporaciones extranjeras, Ya no se contentan en haber implantado en tues. tro suelo las empresas mis lucrativas que poseen en todo ef mundo. Esas mismas empresas que casnto mis ganancia producen y exportan, más nos empobrecen y nos hacen dependientes, tanto a los venezolanos de hoy como a las generaciones venideras.

En efecto, la deuda externa de Veneruela, que era en 1960 de 966 millones de bolivares, aumentó a mís de dos

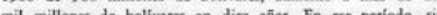

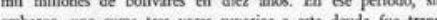
embargo, ana de ferida en calidad de ganancias a las matrices de las empresis que nos explotan, al mismo tiempo que se entriquecieron 


\section{Precisan mantenernos}

callados

Este es el problema con que nos enfrentamos los vene. zolanos de 1970. Pero éste es también el problema de nues. tros explotadores, que precisan mantenernos callados frente esa realidad. ¿Pero cómo os posible silenciar la indignación de la juventud contra un sistema que, ademls de espoliativo en el ámbito internacional, en la órbita interna sólo enriquece a los ricos mientras empobrece a los pobres? El imperativo de someternos, de silenciamos, is lo que impone a los que suen

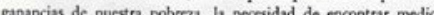
ganancias de nuestra pobrea, th qucsidal de encontrar medios

Asi es como, después de controlar el sistema cconómico, de avasallar el orden politico, de aquietar a los que protestan, los estrategas del sistema empiezan a preoxuparse con la juven tud que madura para el ejercicio de una ciudadania lúcida consciente de la naturatea de la dependencia $y$ de las cases del subdeserrollo. $Y$ se proguntan: colmo caller tas causas

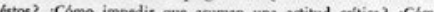
evitur

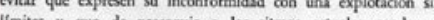
limites y que de proseguir a los ritmos actuales condenar nuestra patria, una vez más, a un papel de nación de segunda categoria en el ámbito de la nueva civilización técnico-cientifica emergente? La contestación la tenemos en el desencadena. miento de esta campuña destinada a doblegar a la Universida autónoma y democrítica en su condición de casa de la juventud que piensa y discute libremente. Los mismos imperativos ha rín indispensuble el intervenir mañana los óreanos de ense ñanza secundaria y primaria, para que no lleguen a formarse venezolanos lúcidos, leales a su patria, capaces de repensarla como conciencia libre de un pueblo tan capaz de progreso como quien mis lo sea.

\section{Nuestra protesta será}

\section{la protesta de la nación}

En esta solemne jornada de nuestra vida autónoma, dejo constancia de mi responsabilidad cipdadana y universitaria, $y$ estoy seguro de que pronto se juntarin muchas otras, hasta que nuestra protesta sea la protesta de la nacion. Serin las voces de los inconformes, de los que no aceptan un sistema que nos condena a asistir de manos atadas al avasallamiento de la Universidad en función del avasallamiento de Veneruela. Cabe preguntar: ecuíl tendtí que ser la consecuencia del avasalla. miento de la última institución libre de este pais? Una ver rota la legitimidad de las autoridades universitarias, sustituidas estas por agentes del gobierno de turno, serí imposible preservat el ambiente de diálogo entre distintas corrientes ideológicas que hasta hoy perduró en la Universidad. Serí imposible comprometer al estudiantado en la preservación del orden $y$ del espiritu democritico de libre debate cormo requisito indispensable al trabajo académico. Al frente de la comunidad universitaria ya no estard una autoridad que sea genuina pot sul orioen institucional $y$ su respetabilidad garantizada, sino una autoridad subalterna cus dignidad estars sometida al apricto del bictno de turno, y un grupo de guardianes alli puetos gobicrno de turs esta. En e funcionario sometido al Ministerio de Educacion y al criterio preestable. cido pot el nuevo y bien controlado Consejo Nacional de Uni. versidades. En el plano interno, tendremos por delante $y$ por encima del menguado Rector al primer policis que decida que es oportuno allanar a Universidad para disciplinar y reprimit a profesores y estudiantes. La quiebra del principio de autoridad propia y legitima sollo conducirá a la anarquia. Esto os to que cosecharin el gobierno y sus socios parlamentarios en sa afán de dar a los explotadores de nuestra patria todo lo que piden, incluso la subversión del sistema de educación de nuestra juventud, para no formarla como veneoolana.

\section{¿A quiénes beneficia esta paz represiva?}

Aun admitiendo la hipótesis absurda de que, mediante la tepresión, se implante en los claustros universitarios el nuevo otden fundado en el miedo, en d silencio y en el servilismo, resulta imperativo indagar: a quienes beneficiaria esta paz represiva? ¿Al pueblo venezolano? ¿A nuestra juventud? No, lo sabemos todos: solo serviria para implantar una universidad elitesa, desnacionalizada y desnacionalizante, dócil a intereses que son ajenos a los nuestros.

\section{Quieren formar tranquilos guardianes del sistema}

En las campañas coatra la autonomia universitaria se dice todos los diss que huy mis estudintes ricos que pobres en nuestra universidad. Mi experiencia de estudiante, de profesor, de decano $y$ de rector me permite afirmat que la mayoria de los jóvenes que ingresan a la universidad enfrentan enormes dificultades para costear sus estudios. Mis de una tercera parte de ellos tiene que trabajur mientras estudia; otros sôlo pueden hacerto merced a las becas que reciben de la Universidad.

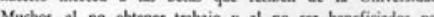
Muchos, al no abtenet trabajo y al no ser beneficises becas, exigen ingentes sacrificios de sus familiares para seguir estudiando.

¿En una universidad elitizada, teprimida $y$ disciplinad: desde afuera, habrá lugar para esta clase de estudiantes? Yo afirmo que no. Es de suponer que la mayotia de los jóvenes que terminan ahora la secundaris encontrarin cetrades las puertas de la Universidad. $Y$ aquellos pocos que alli ingresere

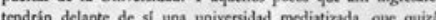
tendrin delante de sif

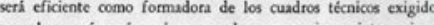
para hacet aún mis próspetos a las corporaciones internaciona les y sus agentes internos, pero que seti un centro estructurado para modelar a tranquilos guardianes del sistema, incapaces de dudar, de cuestionar, de reclamar, porque estarian cons. cientes de que son una minoria superprivilegiada en el mar de I crociente pobreza venezolana. A los problemas del pucblo $y$ de la nación, a sus aspiraciones, sólo se of teceri como soly dón el freno demogrifico que progresivamente habré de con vertirse en genocidio.

¿Es de creer que semejante cosa pueda suceder? ¿Es de creet que tales traiciones se perpetren contra el pueblo $y$ is juventud de Venezuela? ¿Es posible que tantos legisladores elegidos por el pucblo $s$ hayan alejado asi de êl como para transformarse ellos mismos en agentes de la colonización de nuestra patria? 2Es pasible que la ciudadania se quede indiferente ante la neocolonización de Venezuela? 


\section{Mayor alienación}

\section{y completa dependencia}

Es tiempo de abrit los ojos $y$ mitar con coraje la realidad. Es tiempo de indignarse $y$ de luchar, Un pueblo solo pued forjar su destino cuando mantiene en sus manos la formacion de su propia juventud y cuando elabora 41 mismo su proyeciol de futuro. Un pueblo inducido pos falses líteres no teccion

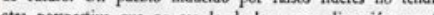
ora persectiva que no sea la de la major alicnación $y$ mis tripir dependtaris tibuir con sa pobreas al enriquecimicnto de sus explotadores no tendra detro futuro que la pérdida de su dignidad hasta el punto en que, como sus falsos lideres, acepte, $y$ aun se habi túe a ellos, los grillos y yuntas con que to encadenan.

¡Este no serí el destino de Venezuela!

Venezuela, que generó los héroes libertadores de América: Venezuela, que a través de mil vicisitudes mantuvo la gallardi $y$ el orgullo de los venezolanos; Venezuela, que construirá un futuro digno de su ayer glorioso, llegarí a unirse toda en Is misma trinchera. Esto porque, al lado nuestro, al lado de los que optaron por el futuro, se encuentra la juventud del pais de todas las corrientes políticas. El propio intento de inspina ción forinea de someter a la Universidad autónoma y democtí. tica $y$ de adueñarse del sistema nacional de educación, est. operando como una fuera movilizadora de la cindadania con. tra la neocolonización de nuestra patria.

La lucha se organizará $y$ creceri, $y$ no podri tener otro signo que el de la victoria!
Los ha formado

la autonomía

Apreciados gradsandos:

Dejan las aulas universitarias en momentes dificiles $y$ tortuosos para L Institución. Es, entonces, mamento oportuno para que renovemos, en una sola profesión de fe, nuestra creencia en la autonomía. El sistema los ha formado $y$ esta concepción que defendemos con tanto celo setí la inspiración para actuar con responsabilidad frente a uas patria que los aguarda, llena de operamas, para que busquemos el camino de su redención definitiva. La Universidad les entrega su representación y espera que hagan honot a ese alto compromiso.

Distinguidos fanwiliares y amiges de quives boy miben uns titwles profesionales:

Ha sido tradición cada vez mís sentida el agradecer a ustedes, en nombre de la Universidad autónoma y democrítica, la generose confianza que depositaron en nosotros al entregat. nos sus seres queridos para la fotmación profesional y ciuda. dana. Hos podemos devolver esa confianza con el triunfo que ellos han logrado sobre la base del sterificio, la aboegación y Ia capacidad. Estamos, si, seguros, de haberlos hecho ciudada. nos con conciencia de patria y profesionales aptos para enfren. tar el reto del tiempo actual. Esta Universidad, tan dolocosimente golpeada por la conjura bustarda espera que ustede sepan valorar lo que signifiós la atonomis on la forja de sus hiijos. $Y$ que, al menos, tengan, con nosotoos, be concis que se que, al menos, tengan, con nostios, la coaciencia de que su cercents

SeNoras y señores:

Cuando las clans voces juveniles del Orfé́n Universita rio interpreten esta tarde nucstro bello himno, estaremos ce

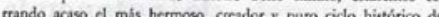

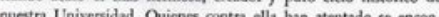
trarin Je trarin, desde ese momento, enfrentados af veredicto de Li historia. Y la historia, como resumen de la inteligencia del hombere, no perdona las traiciones ni a los traidores.

Apreciades graduandos:

En nombre de la comunidad universitaria y en el mio propio, formulo votos porque el éxito siempre los acompañe en el ejercicio de sus carteras profesionales. 